\title{
Denervation of the infraspinatus and release of the posterior deltoid muscles in the management of dyskinetic external shoulder rotation in cerebral palsy
}

\author{
Izabela Blaszczyk, MD, Anna Cecilia Granström, MD, and Mikael Wiberg, MD, PhD \\ Department of Hand and Plastic Surgery, University Hospital of Northern Sweden, Umeå, Sweden
}

OBJECT The dyskinetic subtype of cerebral palsy is difficult to manage, and there is no established gold standard for treatment. External rotation of the shoulder(s) is often managed nonsurgically using injections of botulinum toxin $A$ into the external rotator muscles. This article reports a new surgical technique for managing external rotation when botulinum toxin A treatment is not sufficient or possible.

METHODS Six patients with dyskinetic cerebral palsy underwent denervation of the infraspinatus muscle and release of the posterior part of the deltoid muscle. Postoperative questionnaires were given to the patients/caregivers, and video recordings were made both pre- and postoperatively. Preoperative and postoperative Assisting Hand Assessment was possible in only 1 case.

RESULTS Five patients were very satisfied with their outcome. Four patients' video recordings showed improvement in their condition. One patient developed postoperative complications.

CONCLUSIONS The results indicate that denervation of the infraspinatus muscle and posterior deltoid release can be an option for patients with dyskinetic cerebral palsy to manage external rotation of the shoulder when other treatment alternatives are insufficient.

http://thejns.org/doi/abs/10.3171/2014.9.PEDS14223

KEY WORDS cerebral palsy; external shoulder rotation; upper limb neurotomy; botulinum toxin A; dyskinesia; infraspinatus denervation; functional neurosurgery

$\mathrm{D}$ YSKINETIC cerebral palsy (CP) is a subtype of $\mathrm{CP}$ in which involuntary, uncontrolled, twisting and repetitive movements dominate and muscle tone varies. Sometimes typical movements with primitive reflexes can be observed. Dyskinesia is a result of a brain lesion in the basal ganglia and can affect 1 or more parts of the body..$^{14}$ Surveillance of Cerebral Palsy in Europe ${ }^{3}$ categorized dyskinetic $\mathrm{CP}$ as dystonic $\mathrm{CP}$ or choreoathetotic $\mathrm{CP}$. Dyskinetic $\mathrm{CP}$ is not common and accounts for only $6 \%$ of all cases of CP. ${ }^{1}$ In clinical practice, many patients with $\mathrm{CP}$ present with a mixed form of $\mathrm{CP}$, but their diagnosis is based on the assessment of the predominant motor disorder. ${ }^{7,24}$ Most patients with dyskinetic CP have a severe motor impairment, which means that their potential for independence is extremely limited. Motor impairment can be classified by using the 5-level scores (I-V) of the Gross Motor Functional Classification System (GMFCS), which describes impairment in the lower limbs, and the Manual Ability Classification System (MACS), which describes impairment in the upper limbs. . $, 8,14^{-14}$

Management and assessment of dyskinetic $\mathrm{CP}$ are challenging. The evaluation of treatment results is difficult because of the limited number of available objective measurement tools. The reliability and sensitivity of currently used dystonia scales, such as the Barry-Albright Dystonia Scale and the Beyond the Burke-Fahn-Marsden Dystonia Rating Scale, have been questioned in the assessment of treatment results in patients with dyskinetic CP. ${ }^{8,11,19}$

ABBREVIATIONS AHA = Assisting Hand Assessment; BTX-A = botulinum toxin A; CP = cerebral palsy; DBS = deep brain stimulation; GMFCS = Gross Motor Functional Classification System; ITB = intrathecal baclofen; MACS = Manual Ability Classification System; SPN = selective peripheral neurotomy.

SUBMITTED April 29, 2014. ACCEPTED September 24, 2014.

INCLUDE WHEN CITING Published online January 16, 2015; DOI: 10.3171/2014.9.PEDS14223.

DISCLOSURE The authors report no conflict of interest concerning the materials or methods used in this study or the findings specified in this paper. Grants from the Vasterbotten County Council (to Dr. Blaszczyk) provided funding for the study. 
There are several available treatment options for dyskinesia, including dopaminergic drugs, anticholinergic drugs, benzodiazepines, oral or intrathecal baclofen (ITB) therapy, deep brain stimulation (DBS), and intramuscular injections of botulinum toxin A (BTX-A). All of these treatment options are complementary to each other. ${ }^{24,28}$ ITB therapy is used for generalized dystonic CP and can reduce symptoms successfully, but it is mostly effective in the lower limbs..$^{20,21,24}$ DBS can be used only in limited, well-selected cases of dystonic CP., ${ }^{9,11,24,28}$

The involuntary movements of patients with dyskinetic CP limit the possibility of corrective orthopedic surgery. For example, postsurgical cast immobilization is, in many cases, impossible. However, a number of patients with dyskinetic CP need this treatment because of severe ligament lesions and other muscle or skeletal deformities (e.g., severe scoliosis, shoulder instability, joint dislocation), which can cause pain and postural disabilities.

BTX-A treatment is a therapeutic alternative for managing involuntary movement and hypertonia, especially if they are limited to 1 or 2 parts of the body. The action of BTX-A is chemical denervation, which is dose dependent and reversible. BTX-A injections need to be repeated every 3-6 months for their effect to be maintained. The data on BTX-A treatment for dyskinetic CP are limited, but BTX-A has been used in clinical practice for a relatively long time, according to a consensus established by different interdisciplinary groups of BTX-A users. ${ }^{12,13}$

In our department, we have used BTX-A since 2000 in a total number of 27 patients with dyskinetic $\mathrm{CP}$ to manage their involuntary upper-limb movements. Most of these patients had satisfactory results with repeated BTX-A injections into the affected muscles. We have observed a subgroup of patients with external rotation dystonia in whom repeated BTX-A treatment to the external rotators has been extremely beneficial. However, loss of effect over time or adverse effects prevent further BTX-A treatment in some of these patients. In view of these effects, we have performed surgical denervation via neurotomy instead of chemical denervation of the infraspinatus muscle, a powerful external rotator of the shoulder.

The nerve innervating the infraspinatus muscle (the branch of the suprascapular nerve) consists almost exclusively of efferent motor fibers with probably few proprioceptive afferent fibers; therefore, there is minimal risk for the formation of a painful neuroma after neurotomy. Peripheral neurotomy for the treatment of spasticity was first described more than 100 years ago by Lorenz ${ }^{17}$ (obturator neurotomy) and Stoffel ${ }^{27}$ (median nerve neurotomy). This method was abandoned for many years because of painful neuroma development caused by sensory fiber injury after nonselective neurotomy. In 1975, Gros et al. ${ }^{11}$ developed a selective peripheral neurotomy (SPN) using intraoperative electrical stimulation to identify the motor branch to the muscle of interest that prevents sensory fiber damage. ${ }^{18}$ Techniques and/or results of SPN for the management of upper-limb spasticity have been reported in several studies. ${ }^{2,4,6,18,25,26}$

However, the published results of SPN in the upper limbs of patients with CP have been limited. Msaddi et al. ${ }^{22}$ reported improvement in 2 of 3 children with $\mathrm{CP}$ af- ter SPN of the median and ulnar nerves. In their series of 31 patients, Maarrawi et al. ${ }^{18}$ presented long-term effects on hand spasticity after SPN of the median and ulnar nerves in 3 patients with CP. Fitoussi et al. ${ }^{6}$ reported 18 -month results of SPN of all external shoulder rotators performed in 3 patients with CP with spastic tetraplegia. Sitthinamsuwan et al. ${ }^{26}$ reported a case in which multilevel SPN in the upper limbs (pectoral, musculocutaneus, median, and ulnar nerves) was a part of the management of a mixed form of CP (spasticity and dystonia). Puligopu and Purohit ${ }^{23}$ reported no recurrence of spasticity in 6-20 months of follow-up after SPN in the musculocutaneus and/or median and/or ulnar nerve in 20 patients with CP.

Maarrawi et al. ${ }^{18}$ reported a post-SPN complication in 1 patient with $\mathrm{CP}$, in the form of transitory hypesthesia of the volar part of the forearm resulting from the surgical approach and a lesion of the subcutaneous sensitive branch.

The indications for neurotomy in patients with $\mathrm{CP}$ have not yet been specified. It is unknown if neurotomy is superior to other treatment alternatives, such as BTX-A injection, tenotomy, tendon elongation, or muscle transfer.

In this report, we present the results of a series of 6 patients with dyskinetic $\mathrm{CP}$ who were treated with total neurotomy of the infraspinatus nerve and release of the posterior part of the deltoid muscle. The Swedish Ethical Review Board approved the study.

\section{Methods \\ Patients}

This study included 6 patients ( 5 female and 1 male) between 14 and 24 years of age (mean age 21 years), all diagnosed with dyskinetic CP. Five of the patients were classified as having dyskinetic dystonic $\mathrm{CP}$ with major motor impairment (GMFCS Score IV/V, MACS Score IV/V), meaning that their ability to move independently or handle objects with their hands is very limited. One patient had dyskinetic choreoathetotic CP with minor motor impairment (GMFCS Score II, MACS Score III), indicating that the patient had the ability to walk without assistance but needed help with handling objects. Four patients used a Permobil (electric wheelchair maneuvered with a joystick), but only 2 were able to maneuver it using an upper extremity. Hand function was classified according to House's functional classification system, which is used to assess the ability to grip with each hand separately. ${ }^{15}$ Four patients' conditions were classified as House Grade 4 (poor active assist hand) in their dominant hand. A summary of the patients' clinical characteristics can be found in Table 1.

All 6 patients (7 shoulders) had surgical denervation of the infraspinatus muscle, and 5 patients (6 shoulders) also underwent release of the posterior part of the deltoid muscle.

Before shoulder surgery, each patient was treated with repeated BTX-A injections to the external rotators (posterior deltoid, infraspinatus, and teres minor), and the results of these treatments were considered satisfactory (3-30 treatments during 1-10 years). Three patients received unilateral and 3 received bilateral treatments. The BTX-A treatment goals differed. For 3 patients, the goal was to 
TABLE 1. Clinical characteristics of the patients

\begin{tabular}{clccccccc}
\hline \multirow{2}{*}{$\begin{array}{c}\text { Patient } \\
\text { No. }\end{array}$} & Type of CP & GMFCS & MACS & $\begin{array}{c}\text { House (rt/lt } \\
\text { hand) }\end{array}$ & $\begin{array}{c}\text { Oral } \\
\text { Baclofen }\end{array}$ & ITB & $\begin{array}{c}\text { Previous Orthopedic } \\
\text { Intervention }\end{array}$ & $\begin{array}{c}\text { No. of BTX-A Tx Before } \\
\text { Shoulder Surgery }\end{array}$ \\
\hline 1 & Dystonic & IV & IV & $1 / 4$ & No & No & S, H & 12 \\
\hline 2 & Dystonic & IV & IV & $2 / 4$ & Yes & Yes & S & 30 \\
\hline 3 & Choreoathetotic & II & III & $2 / 4$ & No & No & - & 3 \\
\hline 4 & Dystonic & IV & V & $1 / 0$ & No & Yes & S, H & 9 \\
\hline 5 & Dystonic & IV & V & $0 / 4$ & No & No & M & 7 \\
\hline 6 & Dystonic & V & V & O/0 & Yes & Yes & R & 10 \\
\hline
\end{tabular}

$\mathrm{H}=$ hip surgery; House = House's functional classification system; $\mathrm{M}=$ multilevel surgery in the lower limbs; $\mathrm{R}=$ radial head resection; $\mathrm{S}=$ scoliosis surgery; Tx = treatments.

diminish external shoulder rotation at rest, which disturbs, for example, passage through doors (Fig. 1), and 1 of them (Patient 2) developed bilateral anterior shoulder instability as a result of an external shoulder rotation pattern. In 2 patients, treatment decreased involuntary external positioning of 1 shoulder and arm and improved the use of the other arm. In 1 patient (Patient 4), a reduction of external shoulder movement prevented the left elbow's recurrent dislocation caused by collateral ligament rupture caused by jerky involuntary shoulder movement (Fig. 2).

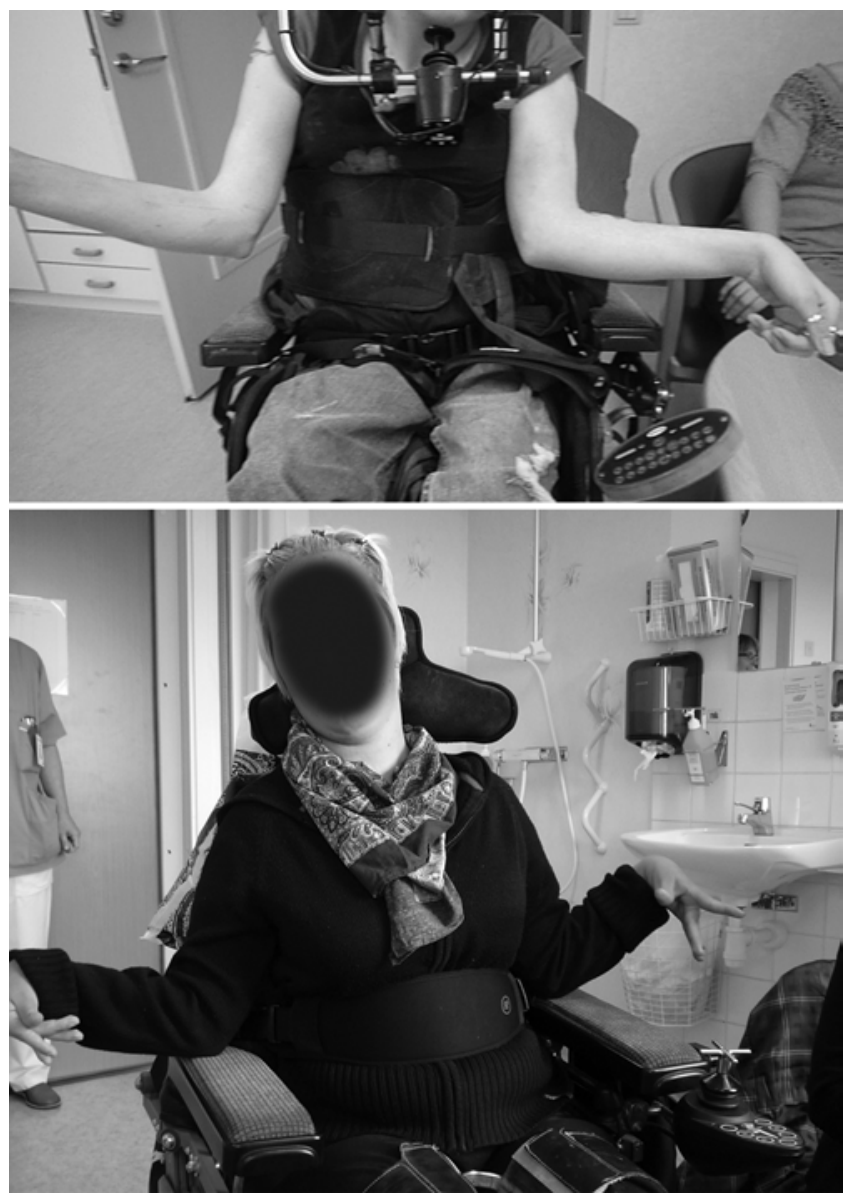

FIG. 1. Preoperative shoulder position of Patients 2 (upper) and 1 (lower).
BTX-A treatment was used in combination with ITB therapy and/or oral baclofen in 3 of the patients. DBS was performed in 1 patient (Patient 2), but despite positive effects, it had to be discontinued because of status epilepticus. Five of the patients (all except Patient 3) had undergone previous orthopedic surgery: 3 for scoliosis (Patients 1, 2, and 4), 2 for hip dislocation (Patients 1 and 4), and 1 (Patient 6) for radial head dislocation; 1 patient (Patient 5) had undergone multilevel orthopedic surgery in the lower limbs (Table 1).

\section{Indication for Surgical Intervention}

In 1 patient, it was not desirable to repeat the BTX-A treatment because of an adverse effect (generalized weakness). In 2 patients, no or minor BTX-A effects were observed. In 3 patients, the duration of BTX-A effects was shorter than 3 months. In addition to denervation of the infraspinatus muscle and release of the posterior part of the deltoid muscle, 3 patients also needed surgical procedures to shorten finger or wrist muscles, for which we performed tendon elongation and/or tendon transfer at the level of the forearm and/or the wrist (Table 2).

\section{Surgical Technique}

Surgery was performed after the induction of general

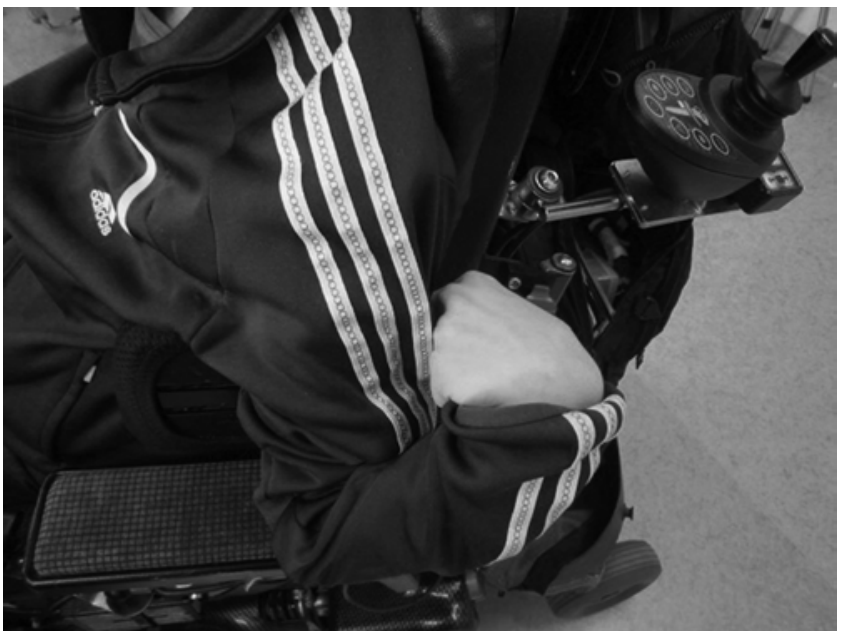

FIG. 2. Elbow instability in Patient 4 caused by jerky external rotation movement of the shoulder. 
TABLE 2. Upper-extremity surgeries

\begin{tabular}{|c|c|c|c|c|c|c|}
\hline \multirow[b]{2}{*}{ Patient No. } & \multirow[b]{2}{*}{ Side } & \multicolumn{2}{|c|}{ Shoulder Intervention } & \multirow[b]{2}{*}{$\begin{array}{l}\text { Hand Op (wrist \&/or } \\
\text { fingers level) }\end{array}$} & \multirow[b]{2}{*}{$\begin{array}{l}\text { Follow-Up } \\
\text { (mos) }\end{array}$} & \multirow[b]{2}{*}{$\begin{array}{l}\text { Adverse } \\
\text { Events }\end{array}$} \\
\hline & & $\begin{array}{l}\text { Infraspinatus } \\
\text { Denervation }\end{array}$ & $\begin{array}{l}\text { Posterior Deltoid } \\
\text { Release }\end{array}$ & & & \\
\hline 1 & $\mathrm{Rt}$ & + & - & + & 38 & No \\
\hline 2 & $\mathrm{Rt} / / \mathrm{t}$ & + & + & $+(\mathrm{rt})$ & 15 & Yes \\
\hline 3 & $\mathrm{Rt}$ & + & + & + & 14 & No \\
\hline 4 & $\mathrm{Lt}$ & + & + & - & 7 & No \\
\hline 5 & Rt & + & + & - & 8 & No \\
\hline 6 & Rt & + & + & - & 6 & No \\
\hline
\end{tabular}

+ = performed; - = not performed.

anesthesia with the patient in a lateral position. After sterile draping, a 6-cm incision was made $1 \mathrm{~cm}$ inferior to the scapular spine, starting from the posterior corner of the acromion. After blunt dissection through the subcutaneous tissue, the muscle fascia was opened, and the posterior deltoid was detached from the spine of the scapula using diathermy. The shoulder joint was then externally rotated, and the infraspinatus muscle was located and retracted. The base of the acromion was identified by palpation. The nerve to the infraspinatus muscle was identified using a nerve stimulator, and care was taken not to damage the adjacent suprascapular artery (Fig. 3). The nerve was totally neurotomized with diathermy as far proximal and distal as possible. The proximal end of the nerve was retracted into the supraspinatus fossa. The nerve innervating the infraspinatus muscle was cut at the level at which the base of the processus acromialis (the end of the spina) is situated, between the fossa supraspinatus and infraspinatus. The base of the processus acromialis is an anatomical barrier for reinnervation, and a gap of $2-3 \mathrm{~cm}$ between the nerve ends created during the neurotomy prevented further reconnection of the ends. In the first patient, the posterior deltoid muscle was reattached to the spine with resorbable sutures to restore the anatomy, whereas in all the other cases, it was left unattached to possibly achieve a better effect. After hemostasis, the

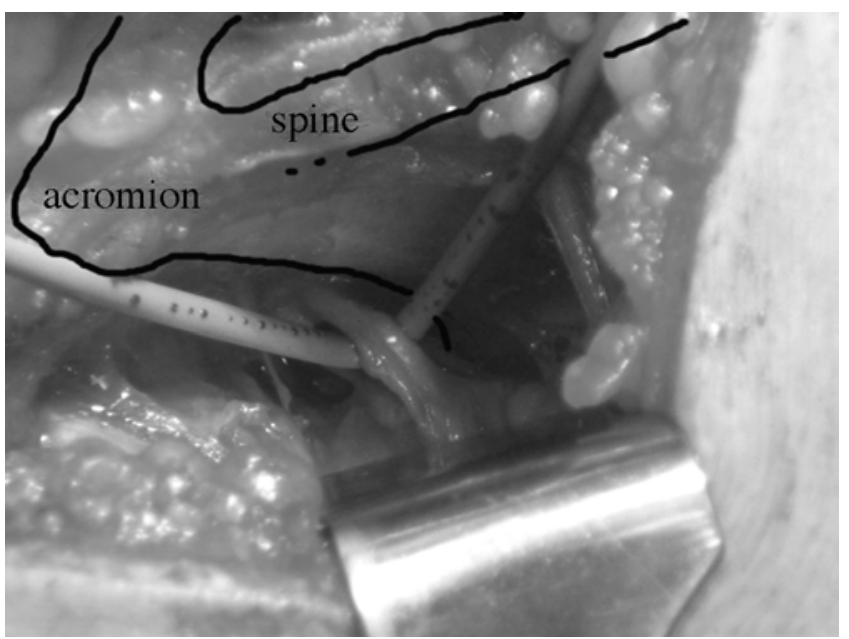

FIG. 3. Nerve dissection. Shown is the nerve to the infraspinatus muscle (under the retractor, left side). fascia was sutured, and the skin was closed. For postoperative pain relief, levobupivacaine was infiltrated in the wound before dressing. The patients had no postoperative restrictions regarding arm mobilization.

\section{Outcome Measures}

Assessing the results of treatment for dyskinesia is difficult, because there is no valid instrument for assessing the changes, especially if the evaluation is focusing on just 1 part of the body (as in our cases [just in the shoulder]). Therefore, we decided to use a postoperative patient satisfaction questionnaire completed along with presurgical and postsurgical video recordings. The video recordings were evaluated repeatedly before and a minimum of 6 months after surgery; we assessed the position of the treated shoulder during rest and activity, if present, and the intensity of involuntary, uncontrolled reflex movements. The follow-up period ranged from 6 to 38 months, which corresponds to the time from surgery until completion of the postoperative patient satisfaction questionnaire. All the patients were able to understand and orally answer the questionnaires, but because of major functional hand impairment, their caregivers filled in the answers. In addition, in 1 patient (Patient 3) who had bimanual task ability, we used the Assisting Hand Assessment (AHA), which is a valid instrument for assessing bimanual hand activity and changes in patients with CP. ${ }^{17}$

\section{Results}

Each patient was discharged on the day after surgery. No early postoperative complications were observed. Four patients had obvious improvement in their shoulder positions on the 1st postoperative day. In 1 patient, there was also a positive effect on the side that was not involved with the surgery (Fig. 4 right). Five of the 6 patients were very satisfied with the operation. No patients were dissatisfied, and there was no observed loss of upper limb function. In 1 patient, the AHA result improved from 41 to 50 logit-based AHA units 6 months after surgery. One patient (Fig. 1 upper and 4 left), who underwent bilateral surgery, developed a complication in the form of an internal rotation pattern in the right shoulder, which was treated with BTX-A injections to the internal rotators. A summary of the patient satisfaction questionnaires is provided in Table 3 . 

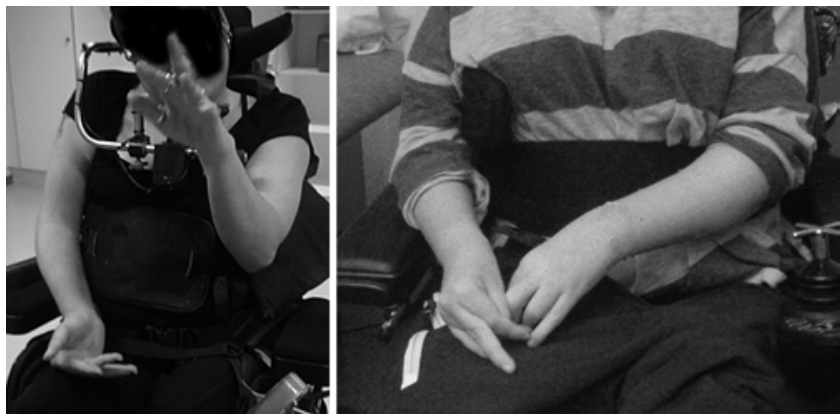

FIG. 4. Postoperative results for Patients 2 (left) and 1 (right).

\section{Discussion}

The dyskinetic subtype of CP is rare and not often treated surgically. Treatment is difficult because of coexisting movement disorders such as involuntary movements, muscle hypertonia, and muscle hypotonia. Pharmacological therapy, ITB therapy, and DBS are treatment options that act on the central nervous system, whereas BTX-A acts peripherally. We have had satisfactory results with repeated BTX-A treatment for patients with dyskinetic CP but have been forced to find other solutions for patients who have intolerable adverse effects or an inadequate therapeutic results. Some patients also wanted a more long-lasting and permanent solution.

Neurotomy as a treatment method for spasticity is not common, but the number of publications on the suitability of SPN in the management of upper- and lower-limb spasticity is increasing. We found only 1 published case report on SPN in a patient with dyskinetic CP. ${ }^{26}$ There is still controversy over whether neurotomy is safe and long lasting. Studies with long follow-up periods supported with objective outcome measurements are needed.

In 2010, 1 year after we initiated the use of surgical intervention for these patients, Fitoussi et al. ${ }^{6}$ published an article in which they described 3 cases of SPN of all external shoulder rotators (teres minor, infraspinatus, and posterior deltoid) for patients with bilateral spastic CP. They evaluated the patients by using passive and active range of motion, the Ashworth scale, and the presence of instability and pain, and they demonstrated improvement in their preliminary results. With dyskinetic $\mathrm{CP}$, passive range of motion is seldom impaired, and the upper extremities have poor function; therefore, active range of motion is not measurable, and muscle tone constantly varies. Therefore, for our patients, the parameters used by Fitoussi et al. are not relevant.

Because the available dyskinesia scales (the BarryAlbright Dystonia Scale or the Burke-Fahn-Marsden Dystonia Rating Scale) ${ }^{8,28}$ are not specific enough to detect focal changes in the upper limb, it was challenging for us to choose relevant measurements to evaluate the surgical outcomes in our study. To detect changes after the surgical procedure in 1 or 2 body parts, we developed our own patient satisfaction questionnaire and repeatedly videotaped each patient before and after surgery. Neither method is perfect, because the evaluations are subjective. The recently published (2012) Dyskinesia Impairment Scale seems to be a valid tool for assessing changes after the different treatments in patients with dyskinetic CP. ${ }^{19}$

In contrast to Fitoussi et al., ${ }^{6}$ we used another approach to solve the external rotation problem. ${ }^{6}$ We chose to totally denervate 1 of the external rotator muscles (infraspinatus), release another (posterior deltoid), and keep the third (teres minor) intact.

In our first patient, we reattached the posterior deltoid muscle. In all the following cases, we left the released muscle unattached. We do not know if reattachment of the posterior deltoid will affect the long-term results, but we think that a long-term follow-up study could answer this question. The first patient noted a positive effect on the side that was not treated surgically. It seems that the diminished number of uncontrolled involuntary movements in 1 arm could help to better control the less impaired side. Initially, before the first surgery, we planned to operate on the other arm, which turned out to be redundant. Maarrawi et al. ${ }^{18}$ also observed distant and collateral effects in the upper limb after SPN; the mechanism of this phenomenon is unclear. We did not observe any significant differences between the first and the following cases that depend on surgical method. The reason might be the high heterogeneity of our small group.

We believe that ours is an adequate way to approach the shoulder when both agonists and antagonists are affected by dyskinesia. However, in 1 patient with a significant complicated preoperative history that involved pain and bilateral anterior shoulder instability (Patient 2), we observed a complication in the form of an internal rotation position of the right shoulder at rest. We explain this

TABLE 3. Results of patient satisfaction questionnaires and video records

\begin{tabular}{|c|c|c|c|c|c|c|c|}
\hline \multirow[b]{2}{*}{ Outcome } & \multirow[b]{2}{*}{ Task } & \multicolumn{6}{|c|}{ Patient No. } \\
\hline & & 1 & 2 & 3 & 4 & 5 & 6 \\
\hline \multirow[t]{8}{*}{ Questionnaire } & Very satisfied & + & + & + & + & + & \\
\hline & Neither satisfied nor dissatisfied & & & & & & + \\
\hline & Better reaching to the mouth & + & + & + & & & \\
\hline & Relaxed arm at rest & + & + & & + & + & + \\
\hline & Easier dressing & & + & & + & + & \\
\hline & Improved sitting balance & & + & & + & & \\
\hline & Improved passage through doors & + & + & & + & + & \\
\hline & Bimanual task improvement & + & + & + & & & \\
\hline Video records & Improvement of shoulder position & + & + & + & + & & \\
\hline
\end{tabular}


as imbalance after neurotomy and managed it by BTX-A injections in the right internal shoulder rotators (pectoralis major and latissimus). This complication was managed successfully with complementary BTX-A treatment. Furthermore the neurotomy created an opportunity to perform an open stabilization of the right shoulder (the Bristow-Latarjet procedure) with excellent results; after 1.5 years, the shoulder was still stable. Before the neurotomy, this patient was treated intensively every 3-4 months for 10 years with BTX-A injections in both external end internal rotators of the shoulders (and in other muscle groups). This patient is still treated with BTX-A injections, but the intensity, muscle number, and total toxin dose per treatment has been reduced significantly.

Preoperatively, we could not determine to what extent each of the 3 external rotators affected the external rotation pattern for each patient. This is one of the limitations with this technique that might be improved by performing more selective BTX-A injections before surgery to help with surgical planning. However, evaluating the results of different injection protocols will always be challenging in dyskinetic patients. We think that there is an option to start surgery treatment with just posterior deltoid release and in cases of insufficient effect to complement infraspinatus denervation in the second surgery.

The different follow-up times were a result of patients treated at different times from the moment we decided to publish the method. The interval between the surgeries of the first and second patients was 2 years. The excellent results in the first patient gave us courage to perform a similar operation in the other. Because this type of disability is not common, we wanted to show how we managed the problem surgically if other treatment methods were not enough. The present study presents a surgical alternative to BTX-A that can give a long-standing improvement and be cost-effective, because it replaces repeated BTX-A treatment in dyskinetic and spastic CP. The procedure can be performed in less than 1 hour as day surgery. The candidates should be selected carefully and be well known to the surgeon.

We are managing just a local dyskinesia symptom in the upper limb and do not treat the dyskinesia or dystonia. We think that we help the patients keep their arms in a more normal and usable position. These patients have a number of difficulties and other medical problems. Arm position is just one problem to manage, but we think that we improved the quality of life for our patients, as reflected by the responses to our questionnaire.

The prognosis depends on many factors, such as level of motor impairment, coexisting disease such as epilepsy and scoliosis, shoulder instability, and intensity of the dyskinesia and spasticity components, which vary in the patients depending on pain or age and contracture formation with time. To make decisions on surgery, we are working in a team together with occupational and physical therapists, neurologists, and neurosurgeons.

This is a study with a limited number of patients and a relatively short follow-up time; therefore, further evaluation of the results will be needed to establish the longlasting effects and to verify that no adverse effects will be observed at longer time points after surgery. We plan to present the 5-year follow-up results by performing electromyography and ultrasonography of the patients' infraspinatus muscles to assess the long-term effect of neurotomy.

\section{Conclusions}

The results indicate that denervation of the infraspinatus muscle and posterior deltoid release can be an option for patients with dyskinetic CP to manage external rotation of the shoulder when other treatment alternatives are insufficient.

\section{References}

1. Andersen GL, Romundstad P, De La Cruz J, Himmelmann K, Sellier E, Cans C, et al: Cerebral palsy among children born moderately preterm or at moderately low birthweight between 1980 and 1998: a European register-based study. Dev Med Child Neurol 53:913-919, 2011

2. Buffenoir K, Rigoard P, Ferrand-Sorbets S, Lapierre F: [Retrospective study of the long-term results of selective peripheral neurotomy for the treatment of spastic upper limb. Neurochirurgie 55 Suppl 1:S150-S160, 2009 (Fr)

3. Cans C: Surveillance of cerebral palsy in Europe: a collaboration of cerebral palsy surveys and registers. Dev Med Child Neurol 42:816-824, 2000

4. Decq P, Filipetti P, Feve A, Djindjian M, Saraoui A, Kéravel Y: Peripheral selective neurotomy of the brachial plexus collateral branches for treatment of the spastic shoulder: anatomical study and clinical results in five patients. J Neurosurg 86:648-653, 1997

5. Eliasson AC, Krumlinde-Sundholm L, Rösblad B, Beckung E, Arner M, Ohrvall AM, et al: The Manual Ability Classification System (MACS) for children with cerebral palsy: scale development and evidence of validity and reliability. Dev Med Child Neurol 48:549-554, 2006

6. Fitoussi F, Ilharreborde B, Presedo A, Souchet P, Penneçot GF, Mazda K: Shoulder external rotator selective neurotomy in cerebral palsy: anatomical study and preliminary clinical results. J Pediatr Orthop B 19:71-76, 2010

7. Gainsborough M, Surman G, Maestri G, Colver A, Cans C: Validity and reliability of the guidelines of the surveillance of cerebral palsy in Europe for the classification of cerebral palsy. Dev Med Child Neurol 50:828-831, 2008

8. Gimeno H, Gordon A, Tustin K, Lin JP: Functional priorities in daily life for children and young people with dystonic movement disorders and their families. Eur J Paediatr Neurol 17:161-168, 2013

9. Gimeno H, Lumsden D, Gordon A, Tustin K, Ashkan K, Selway R, et al: Improvement in upper limb function in children with dystonia following deep brain stimulation. Eur J Paediatr Neurol 17:353-360, 2013

10. Gimeno H, Tustin K, Selway R, Lin JP: Beyond the BurkeFahn-Marsden Dystonia Rating Scale: deep brain stimulation in childhood secondary dystonia. Eur J Paediatr Neurol 16:501-508, 2012

11. Gros C, Frerebeau P, Benzech J, Privat JM: Neurotomie radiculaire sélective, in Simon L (ed): Actualités en Réeducation Fonctionelle et Réadaption. Paris: Masson, 1977, pp 230-235

12. Guettard E, Roze E, Abada G, Lemesle C, Vidailhet M, Laurent-Vannier A, et al: Management of spasticity and dystonia in children with acquired brain injury with rehabilitation and botulinum toxin A. Dev Neurorehabil 12:128-138, 2009

13. Heinen F, Desloovere K, Schroeder AS, Berweck S, Borggraefe I, van Campenhout A, et al: The updated European Consensus 2009 on the use of Botulinum toxin for 
children with cerebral palsy. Eur J Paediatr Neurol 14:4566,2010

14. Himmelmann K, McManus V, Hagberg G, Uvebrant P, Krägeloh-Mann I, Cans C: Dyskinetic cerebral palsy in Europe: trends in prevalence and severity. Arch Dis Child 94:921-926, 2009

15. House JH, Gwathmey FW, Fidler MO: A dynamic approach to the thumb-in palm deformity in cerebral palsy. J Bone Joint Surg Am 63:216-225, 1981

16. Krumlinde-Sundholm L: Reporting outcomes of the Assisting Hand Assessment: what scale should be used? Dev Med Child Neurol 54:807-808, 2012

17. Lorenz F: Über cirurgische Behandlung der angeborenen spastischen Gliedstarre. Wien Klin Rdsch 21:25-27, 1887

18. Maarrawi J, Mertens P, Luaute J, Vial C, Chardonnet N, Cosson M, et al: Long-term functional results of selective peripheral neurotomy for the treatment of spastic upper limb: prospective study in 31 patients. J Neurosurg 104:215-225, 2006

19. Monbaliu E, Ortibus E, De Cat J, Dan B, Heyrman L, Prinzie $\mathrm{P}$, et al: The Dyskinesia Impairment Scale: a new instrument to measure dystonia and choreoathetosis in dyskinetic cerebral palsy. Dev Med Child Neurol 54:278-283, 2012

20. Motta F, Stignani C, Antonello CE: Effect of intrathecal baclofen on dystonia in children with cerebral palsy and the use of functional scales. J Pediatr Orthop 28:213-217, 2008

21. Motta F, Stignani C, Antonello CE: Upper limb function after intrathecal baclofen treatment in children with cerebral palsy. J Pediatr Orthop 28:91-96, 2008

22. Msaddi AK, Mazroue AR, Shahwan S, al Amri N, Dubayan $\mathrm{N}$, Livingston D, et al: Microsurgical selective peripheral neurotomy in the treatment of spasticity in cerebral-palsy children. Stereotact Funct Neurosurg 69:251-258, 1997
23. Puligopu AK, Purohit AK: Outcome of selective motor fasciculotomy in the treatment of upper limb spasticity. $\mathbf{J}$ Pediatr Neurosci 6 (Suppl 1):S118-S125, 2011

24. Roubertie A, Mariani LL, Fernandez-Alvarez E, Doummar D, Roze E: Treatment for dystonia in childhood. Eur J Neurol 19:1292-1299, 2012

25. Sindou MP, Simon F, Mertens P, Decq P: Selective peripheral neurotomy (SPN) for spasticity in childhood. Childs Nerv Syst 23:957-970, 2007

26. Sitthinamsuwan B, Chanvanitkulchai K, Nunta-Aree S, Kumthornthip W, Pisarnpong A, Ploypetch T: Combined ablative neurosurgical procedures in a patient with mixed spastic and dystonic cerebral palsy. Stereotact Funct Neurosurg 88:187-192, 2010

27. Stoffel A: The treatment of spastic contractures. Am J Orthop Surg 10:611-644, 1912

28. Tierney TS, Lozano AM: Surgical treatment for secondary dystonia. Mov Disord 27:1598-1605, 2012

\section{Author Contributions}

Conception and design: Blaszczyk. Acquisition of data: Blaszczyk, Granström. Analysis and interpretation of data: Blaszczyk, Granström. Drafting the article: all authors. Critically revising the article: all authors. Reviewed submitted version of manuscript: all authors. Approved the final version of the manuscript on behalf of all authors: Blaszczyk.

\section{Correspondence}

Izabela Blaszczyk, Department of Hand and Plastic Surgery, University Hospital of Northern Sweden, Akutvägen 1, 90185 Umeå, Sweden. email: izabela.blaszczyk@vll.se. 